\title{
Tuning to the Right Words
}

\section{Maria Grazia Spurio*}

Genius Strategic Counseling School via C.A. Jemolo, Rome, Italy

"Corresponding author: Maria Grazia Spurio, Psychotherapist, Master in Neuropsychiatry and Forensic Psychology, Director of Genius Strategic Counseling School via C.A. Jemolo 83 ROME, Italy, Tel: 92-00187377-7; E-mail: dott.m.g.spurio@hotmail.it

Rec date: May 30, 2016; Acc Date: July 11, 2016; Pub Date: July 17, 2016

Copyright: ( 2016 Spurio MG. This is an open-access article distributed under the terms of the Creative Commons Attribution License, which permits unrestricted use, distribution, and reproduction in any medium, provided the original author and source are credited.

\begin{abstract}
The considerations argued in this article start from the valuable healing that words can express well, that pass through the issues of communication, the use of words that heal in psychotherapy, to get to their use in clinical practice. Thanks to the music of the words patients understand their discomfort, and become able to choose new words to redefine, re talk about and find a new personal "sound of healing". The plot of exchanges and relationships between brain chemistry and the right words to heal is subtle and intricate. The same use of language is metaphor from another metaphor. The sensory experience of each individual, in fact, is not objective reality, but an elaboration of it, a map of reality. On this basis people choose the words that best represent it. Psychotherapy, the talking cure, has proved to be a treatment that directly affects the brain and is able to change it permanently, arriving to interest the anatomical structure and function. Caring healing is not only alleviating or eliminating pain, but also trying to tell and share. When the patient tells a pain or a loss, by choosing the right words to do so, it seems everything may become more bearable. The passions aroused by well-chosen words would then be the main way to go to achieve a tuning interior, the whole human capacity to play together all the parts of which we are made.
\end{abstract}

Keywords: Change; Healing; Language; Words that heal

\section{The Language able to Lead to a Change}

Words are the tools of the profession of a psychotherapist, through words he/she can build, modify and interpret reality. Of course, we are talking about the correct words, because, if not correct, they can cause a lot of pain and hurt. On the contrary, if well used, they have the power to heal, improve life, re-establish, they can have a beneficial and refreshing sound: the sound of healing.

Everyone should use words in an ethical way, but it becomes a 'must' in the context of helping a relationship, as the therapist must be a professional of the words, and, by their sound, can create a magical music, the music of healing. To make this possible a "professional" of the word must be ready to abnegate the absoluteness of his or her theories, and at the same time he or she must similarly be ready to give up a specific language in order to tune with that of the person who enters into a relationship of help, then, he or she will gradually introduce new words, with new concepts, that are functional to the goal. The person entering the helping relationship therapy is no longer a 'prisoner' of impulses, instincts and energy forces, but an individual who helps to build one's own reality through a personal conception of it, or its internal representation, that led to have a personal and located knowledge. The role of communication in this dynamism, however, appears very important: through it, in fact, one begins to agree with his partner on a common ground of understanding the experience that goes through the use of language. In this we recognize the principles of constructivism and constructionism, in comparison to which the individual is considered an active builder of his own experience.

Thus, the pre-established and static therapeutic model is switched into a more flexible vision, somehow conditioned by the particular ability of the therapist. The strategic therapy bases on constructivism the assumption that the construction of reality passes through an individual dimension, and on constructionism the principle that the group and the interactions between its members are at the center of attention. If we talk about interaction, it is necessarily to study the language. Everyone has ideas, layouts and concepts of oneself. They are considered functional or dysfunctional, according to the different situations and with the aim of coherence in the cycle social role identity and self. A person comes often to therapy because something is jammed in the mechanism. He or she does not find the keys to interprete his or her life, feeling that 'something must be wrong'.

Then the therapist has to give back a lost image of the selffunctioning individual, an image that well fits into his belief system, or even get to change it partially. The narrative becomes a fundamental part of the practice, here once again the importance of the concept of the words. Here are the words that the patient chooses, in telling himself and his own experiences. For his part, the therapist must accept, and if necessary, change them and give back new ones. The way from content to process, from how to why, from the search for what is true to the search of what is useful. In more recent times, the rich tradition of the School of Palo Alto has made tremendous contributions to the formulation of the model of Brief Therapy. In the '70s, in fact, the group of the Mental Research Institute in Palo Alto presented to the community of therapists the results of the project "Brief Therapy Center": the world is the consequence of human experience and not its cause [1]. Strategic therapy, then, becomes a mode of understanding of the current and conscious, rather than the past and the unconscious. The investigation of the patient, according to the Palo Alto School, should be reduced to a minimum with regard to the past and the previous, current and more focused behavior. These behaviors are seen in their homeostatic function, namely thesis maintain an overall balance, though enough of a dysfunctional structure. Therefore, the effort is directed to propose a new balance by modification of a part of the whole. A change in one part of the system then generates a total reorganization in order to maintain the homeostatic equilibrium. 
Page 2 of 5

Procedures designed at Palo Alto debunk other myths typical of the classical, such as the times change and the responsibility of the therapist. Far from remaining bound to the idea that the more serious the disorder was the longer should be the times for change, the experiences of the Brief Therapy Center were not relevant mathematical connections. Indeed, most of the cases could be treated in a short time with results at least equal to those of traditional therapy. Regarding the responsibility of the therapist, in the approach to Palo Alto he is the major player in producing the changes needed, and for the duration of the therapy he keeps the directive. It does so with active manoeuvres that is able to break the rigidity of the system which keeps the problematic situation. He does this through the right choice of words.

Watzlawick [1,2] stated that different versions of the reality perceived pass through communication, and not through objective data. This peculiar power of communication seems now a concept strongly accepted, as well as the assumption that the noncommunication doesn't exist, because besides the spoken language, or verbal communication, there is another one that is not made of words but exercising the same moulding power on reality and people. In this paper we have chosen to deal with communication of words, words that heal.

With the concept of healing, we can refer to individuals who have developed a condition detectable by a diagnostic point of view, such as schizophrenics $[3,4]$. They come to distort the meaning of language, as well as their perception of behavioural significance of people around them. From this point of view, they react with the strategy to imagine themselves being another person. In doing so, the pain shifted to another person is not real, and the task of those who must choose the words that heal is to understand who the 'active self' of the moment is and which the right level of communication for the moment is. In communication pathology, of which Haley was one of the pioneers, it is very important to change also the terminology, in order to avoid being framed in fixed diagnostic categories that do not correspond to reality of the individual. So, also in the perspective of the therapist, the choice of words, begin to produce a positive result even before they are directed to the individual in need of therapeutic support (Figure 1).

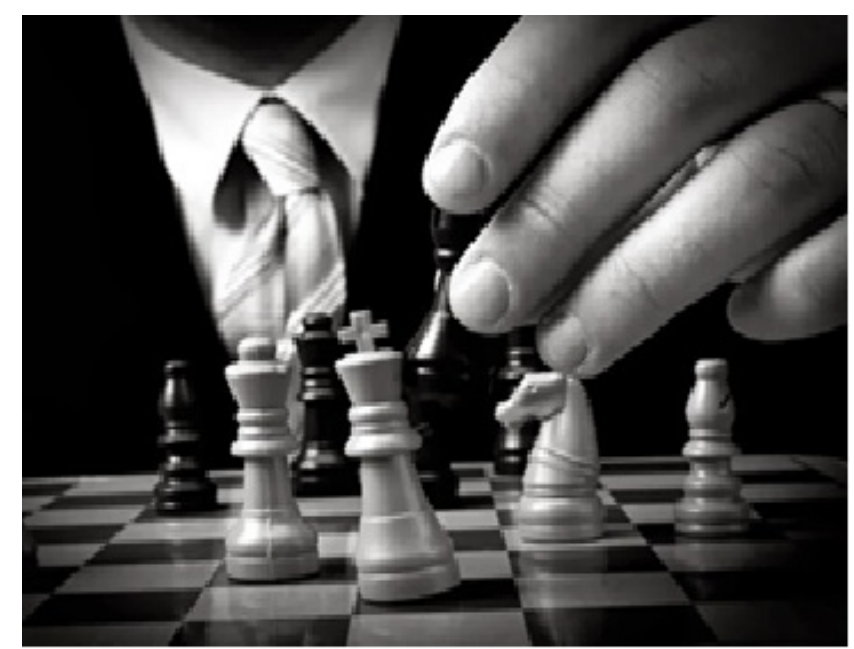

Figure 1: The positive therapy for therapeutic support.
The model of the Palo Alto school offers treatment techniques based on suggestive communication, intended as the strategic move more suitable to be used during psychotherapy, comparable to a 'game of chess' [5]. Among the communication tools we can mention suggestive metaphors, paradoxes, the hypnotic communication [6], about the role and the power of suggestion that passes through the choice of words in obtaining therapeutic changes, lays the foundation of the emerging strategic psychotherapy. This psychotherapy is different from others as it states that the psychotherapist has a role of central importance. He, in fact, between the various choices that have been in the identification of the most suitable therapy for a specific case, operates one choice of fundamental importance regarding the language.

The language used by the strategic communication can be defined both suggestive and injunctive. With suggestive language we mean one of the two major strategies of intervention, in addition to the requirements of behavior, in the approach of psychology strategically oriented to produce a change. To implement effective communication, and then to adopt a type of language that can be said to be impressive, you must first learn to use the language of the person who presents his problem. This communication technique, although already well known in classical rhetoric, comes, in its strategic sense, from Erickson's hypnosis [7]. Aristotele said that if you want to persuade someone to do something you must use his own arguments. We might add that, in part, it may be through his own words. In strategic intervention, the operator listens very carefully to the words chosen by his client. $\mathrm{He}$ tries to understand his global expectations, fears, hopes, prejudices, and also the way in which they are expressed. In terms of language, in fact, we know that the choice of vocabulary of a person reveals a great deal about his primary cognitive perception of the world. We may define these perceptions representational systems, as they represent the reality without being it. The representational systems are conditioned by the five sensory systems at our disposal to get in touch with physical reality, a kind of 'input channels': sight, hearing, coenaesthesia, smell and taste. Sensory information coming through each of these elements, set in motion the behavior of the 'individual and help him to organize the experience. Of these sensory channels, some have prevalence on others, that is, the system valued by the person the most [8]. So, for someone 'to see' will literally begin 'to believe', for others it will be important how things will play for him and for others everything will depend on the contact and the pleasure of things. The language you use to represent their experience evokes in the listener different nuances depending on the primary channel used.

It has happened people have lived the same experience with the same content, but while telling it, they corrected each other. The difference is in how the data are collected, which plan is most sensitive; someone reacts to those visual stimulations, someone else to hearing ones. Then, the most importance thing is to recognize the "language" of the other in order to be tuned to his experience. Knowing how to speak the language of its stakeholders helps to understand and to be better understood. The first step is to pay attention to the language of those who are ahead of us and particularly to the predicates used to express his experience, such as adverbs, adjectives and verbs. After having detected which predicates are most frequently used by our interlocutor, we can try to tune to the same ones. This approach allows us to facilitate the process of receiving, thus avoiding any communication disorders due to the difficulty to understand something that is not part of his model of the world. Of course, the language correspondence cannot be separated from a behavioural one, in order to give, to the listener, the feeling of being fully understood and therefore create the right conditions for effective communication. 
The choice of the right words is fundamental also in the process of positive connotation, that is, when an active collaboration and participation is hoped in subjects a bit 'stiff' in their positions. The more productive attitude is to reward the person and through this gratification it is possible to produce behavioral changes. In this communication, the resistance is circumvented, people feel gratified and encouraged to continue doing what they were already doing with new behavioral actions, but that contradict what they had started.Among the finest persuasion techniques we find restructuring. Restructuring means to recode the perception of the reality of a person without changing the meaning of things, but changing the structure. It is not to change the semantic value of what the person expresses, but the frames of significance, with the consequence, of course, of changing the meaning [9]. Restructuring can be both a purely verbal communicative acts and specific action, leading the person in a shift of perspective. On the other hand, in the technique of illusion of alternatives, the client is called to make a choice between two alternatives, however illusory, because, despite their apparent authenticity, they both represent one pole of a pair of opposites.

Another persuasive technique implemented through the use of language is anticipation. Anticipation requires an assent, as it indirectly defines the disagreement as a demonstration of lack of understanding, lack of imagination, or limited intelligence.

An example of it is the use of expressions like: "You'll find it foolish, but I feel that ...." "It will seem ridiculous, but you could say that ..." "There is a very simple solution, that she definitely does not like it .....Among the most effective forms of communication is the paradox that is a kind of logic trap in which all the classic rational logic drops. It undermines the Aristotelian logic of "true or false", and the manichean optical of the pairs of opposites (black / white, good / bad, right / wrong) used as categories to describe reality. The use of anecdotes is similarly effective: a mode of communication that, through stories and metaphorical language minimizes drag, since the person is not subject to direct requests or judgments on his way of thinking and behaving. The message arrives veiled, in the form of a metaphor. The same use of language is a metaphor from another metaphor. The sensorial experience, in fact, is not the objective reality, but a processing of it, a map of reality. On this basis, the people choose the best words to represent it. The maps consist of sensory-perceptual linguistic distinctions that give meaning to the world; they are related to the emotional sphere, even if they start from physical sensations, memory, etc. The metaphor, thus, is referred both to the personal map of reality and to the ideological assumptions and perceptive shared with other people as members of the same culture. "Metaphors are a way to share experiences." [10].

The use of metaphor is oriented to the production of changes. The narrative is based on the hope that the experiences represented suggest functional ways to deal with the situation. They can be told to anyone in a simple and easily way, and accepted, although if not exactly conform to the reference map of the listener. In fact they are more interesting than a direct exposure of the things that have to be emphasized and communicated. A well-developed and well-told story, which necessarily passes through the choice of the right words, or words that heal, can capture the imagination and move the person to take actions that he had never even considered. The stories deal with an issue in a discreet way, leaving the possibility to use insights in a personal way, not too painful or bothersome. We must not underestimate the fact, also, that a story helps to establish a relationship with people, to build up a model of good communication and full of possibilities. Anecdotes emphasize, or illustrate, something using the language of poetry, story, theatre, non-verbal language. This is the language of imagination, of the right hemisphere, different from the left hemisphere one that instead expresses the objects in logical and well-defined ways, framed in a scheme of ordered syntactic rules.

We therefore have to deal with two types of languages. One is objective, cerebral, logical, and analytical. It gives definitions, is the language of reason, of science, of interpretation and explanation, as well as the language of most therapies. The other one is much more difficult to define, because it is not the language of the definition. It could be called the language of 'image, metaphor, pars pro to, perhaps for the symbol, but in all cases of the totality (and not of the analytical breakdown) [1].

\section{The Sound of Healing}

According to Kandel [11], one of major living scientists, Nobel Prize winner for medicine, physiology, and an American neurologist and psychiatrist, psychotherapy is a real cure, a biological treatment, as it produces behavioral changes through new words, new experiences and new learning that causes documented changes: the alteration of synaptic connections, or the interconnections of neurons, determines structural changes in the brain, that operates on anatomical models of interconnection of the nerve cells. Kandel started his studies with the behavior and nervous system of Aplysia, a small snail, and in the time has come to extend the discoveries to learning processes of humans. The discovery was revolutionary and has opened a new way of approaching the neurological studies related to psychological behaviors and in particular in the learning process. The central idea is that understanding the biological processes of learning and memory opens the possibility to understand the behaviour of people and their disorders and psychiatric symptoms. This insight has represented a breakthrough in neuroscience and has led the way to interconnected studies between different fields, such as biology, psychiatry and psychotherapy. The improvement, helped by the use of techniques, visualization and investigation of the brain, has offered a more accurate evaluation on quantitative and qualitative influence of psychotherapy on brain functioning. The experimental research provides an understanding of human development in an extraordinary way that reminds the principles of Freudian psychoanalysis.

There are convincing proofs of the existence of the unconscious. It is proved that most of the complex mental life is unconscious; people experience thoughts and emotions of which they are unaware. Psychoanalysis helps to understand childhood trauma and is a powerful tool for change and growth. If we think that it is a road made mostly of words, we understand what it means that words have the power to treat. The therapeutic process allows the recovery of memory, to live a new experience through the relationship of transfer with the analyst. Psychoanalysis can go back to childhood trauma and current, process them and integrate them, it is therefore a powerful tool for change and growth. If we think that it is a road made mostly of words, then we understand what it means that words have the power to cure. The therapeutic process allows well to recall the memory, to live a new experience through the relationship of transference and counter-transference with the analyst.

Kandel [11] argues that psychoanalysis offers vision of the mind more coherently and satisfactory from an intellectual point of 
view... there is reason to believe that the biology of the mind will be the main area of research in the twenty-first century, like the biology of the gene has been in the second half of the twentieth. Psychotherapy, treatment with words, produces documented changes in the brain. Among the very first step along the path of change, we find, as repeatedly argued, the choice of words, right words. The patient arrives, he begins to talk about himself, and already through the choice of the words he does, the therapist is able identify what kind of disease he is experiencing. Then, the therapist tunes, like a radio station, to its frequencies, to the same language, and gradually offers him the possibility to be tuned to another frequency, by using other words, words that heal.

\section{Conclusion}

Everyone is a unique universe, the alchemy produced by the combination of genetic heritage and circumstances of life, such as social and working opportunities, creates a myriad of possible outcomes and different possibilities of the development of potential. It is therefore up to the preparation of the therapist, being able to capture and interpret languages and messages, even if they are silent and unconscious, but always full of meaning. This is a complex and precious personal universe that it is not possible to live aside when one want to pursue the objective of therapeutic improvement [12-14].

The research on the placebo effect of Benedetti $[15,16]$ has significantly contributed to explain the complexity of these interactions. For a long time the placebo effect has been a considered in a very simplistic way, until research has begun to clarify the complexity of the emotions that bring the mind and body to meet Ruggiero and Icone [17]. Trust in the words strategically chosen and well used by the therapist, coach or trainer, cause ripple effects benefits, with activation of the prefrontal dorsolateral cortex, a beneficial neural tune that may cease without the use of restorative words.

The psychotherapist must therefore be an excellent professional who uses the right words to heal strategically and carefully, because when this happens during psychotherapy, a very effective process of activation of brain areas can start, in addition to those stimulated by the placebo effect (the left prefrontal area); furthermore it has been found an increasing activity in inter-hemispheric (right / left) and a significant increase of the connections of the callosum corpus [15]. For Carderi et al. [18] respect and listening are essential to establish rapport, i.e., a trustful relationship with the unconscious mind, where the quality of the therapist penetrates interpersonal relationships. Nevertheless, according to the authors, the instrument to establish rapport is 'tracing. The tracing consists in reflecting the behavior of the patient in order to communicate: "you exist for me!" "I understand you," and then "I am able to help you." [18].

It is with ethical attitude that the therapist assumes responsibility as a part of the reality that he belongs to. Understanding weaknesses or deficiencies is the way to see and understand those of others. The prejudices, lack of self-criticism, arrogance, and disrespect are the causes and consequences of many misunderstandings. It is increasingly necessary to move towards social, personal and organizational objectives that have higher goals than profit, and the first step in this direction is to learn to respect others through projects like a self-efficacy window and the improvement of people innovatively. To deeply respect himself and others means to live with dignity and with the responsibility of human relationships.
For this reason it this must be re-evaluated the value of making a psychological and ethical commitment towards the other, as individuals that are part of the society in the broadest sense of the term. The words chosen both in therapeutic contexts and in everyday life have to be re-evaluated, well aware of the great and magical potential of healing and change that words can activate.

Since 1996 LeDoux contrasted the features of top-down psychotherapy that allows the patient to gain new experiences that help grow, from the bottom-up process of the drug. The complement of the two approaches helps us to understand the profound connection that exists between words and care and their extraordinary healing power. According to Ruggiero and Icone [17], we can say that when the word becomes a gesture, vibration and sound, it encourages contact with a deep part of ourselves, the word "I" becomes care, curiosity, eagerness, and an attitude of the soul. Care healing is not only alleviating or eliminating pain, but also in trying to tell and share. "All the pains and losses are bearable if you insert them into a story, if one tells a story on them" Cavarero [19]. The passions aroused by well-chosen words are therefore the main way of achieving an interior tuning, the whole human capacity to play together all the parts of which we are made. Of course, this is not possible without the work of a "resonant" therapist that thinks, listens, takes care of the relationship with the other [17], and who, just as with refreshing music, conveys its beneficial intervention through strategically chosen words to heal.

\section{References}

1. Watzlawick P (1977) The language of change of therapeutic communication elements. Feltrinelli.

2. Watzlawick P (1976) The reality of reality. Astrolabe.

3. Zeig JK, Erickson MH (1985) An introduction to the man and his work. Astrolabe.

4. Erickson MH (1988) The mind communication - body in hypnosis. Rome, Astrolabe.

5. Rogers C (1963) Psychotherapy today, now where do we go from here? American Journal of Psychotherapy 17: 5-6.

6. Haley J (1973) Uncommon Therapy. The Psychiatric Techniques of Milton Erickson. W.W.Norton \& Company.Inc, New York.

7. Amman M, Stern D (1991) Representations and narratives. Bari, Laterza.

8. Verrastro V (2004) Psychology of Communication: An introductory manual. Milan, Franco Angeli.

9. Gordon D (1978) Therapeutic metaphors. San Diego, Cupertino.

10. Kandel ÉR (1999) Biology and the future of psychoanalysis: A new intellectual framework for psychiatry revisited. Am J Psychiatry 156: 505-524.

11. Spurrier MG (2015) The sound of healing.

12. Spurrier MG (2015) Words That Heal. Psychiatria Danubina 27: 21-27.

13. Spurrier MG (2011) Milton Erickson and Pet therapy. Which Psychology.

14. Benedetti F, Molinari E, Castelnuovo E (2010) Clinical psychology of pain. Milan, Springer.

15. Benedetti F (2012) The placebo effect. Short trip between mind and body. Roma, Carocci.

16. Ruggiero G, Icons S (2014) The Invisible shirts. The emotions in the relationship of care. Ideas Psicoterapia.

17. Carderi A, Petruccelli F, Verrastro V (2013) Sexual therapy in hypnosis. Alpes.

18. Cavarero A (2001) You look at me, you tell me. The narrative philosophy. Feltrinelli.

19. Siegel D (2008) Mindfulness and Brain. Cortina. 